\title{
Introduction of universal prestorage leukodepletion of blood components, and outcomes in transfused cardiac surgery patients
}

\author{
Zoe K. McQuilten, MBBS,, a,b,d Nick Andrianopoulos, MBBS, MBiostat, ${ }^{a}$ Leo van de Watering, MD, PhD, \\ Cecile Aubron, PhD, ${ }^{\mathrm{b}}$ Louise Phillips, PhD, ${ }^{\mathrm{a}}$ Rinaldo Bellomo, MBBS, MD, ${ }^{\mathrm{b}, \mathrm{f}}$ David Pilcher, MBBS, ${ }^{\mathrm{b}, \mathrm{g}}$ \\ Peter Cameron, MBBS, MD, ${ }^{a}$ Christopher M. Reid, PhD, ${ }^{a}$ Merrole F. Cole-Sinclair, MBBS,

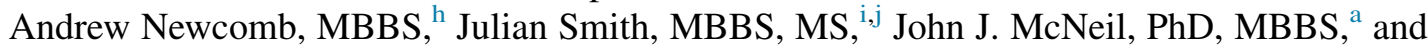 \\ Erica M. Wood, MBBS ${ }^{\mathrm{a}}$
}

Objective: To assess whether introduction of universal leukodepletion (ULD) of red blood cells (RBCs) for transfusion was associated with improvements in cardiac surgery patient outcomes.

Methods: Retrospective study (2005-2010) conducted at 6 institutions. Associations between leukodepletion
and outcomes of mortality, infection, and acute kidney injury (AKI) were modeled by logistic regression, and
intensive care unit length of stay (LOS) in survivors was explored using linear regression. To examine trends
over time, odds ratios (ORs) for outcomes of transfused were compared with nontransfused patients, including
a comparison with nontransfused patients who were selected based on propensity score for RBC transfusion.

Results: We studied 14,980 patients, of whom 8857 (59\%) had surgery pre-ULD. Transfusions of RBCs were made in 3799 (43\%) pre-ULD, and 2525 (41\%) post-ULD. Administration of exclusively leukodepleted, versus exclusively nonleukodepleted, RBCs was associated with lower incidence of AKI (adjusted OR 0.80, 95\% confidence interval $[\mathrm{CI}] 0.65-0.98, P=.035$ ), but no difference in mortality or infection. For post-ULD patients, no difference was found in mortality (OR $0.96,95 \%$ CI $0.76-1.22, P=.76$ ) or infection (OR $0.91,95 \%$ CI $0.79-1.03, P=.161$ ); however, AKI was reduced (OR $0.7995 \%$ CI 0.68-0.92, $P=.003$ ). However, ORs for post-ULD outcomes were not significantly different in nontransfused, versus transfused, patients. Furthermore, those who received exclusively nonleukodepleted RBCs were more likely to have surgery post-ULD.

Conclusions: Universal leukodepletion was not associated with reduced mortality or infection in transfused cardiac surgery patients. An association was found between ULD and reduced AKI; however, this reduction was not significantly different from that seen in nontransfused patients, and other changes in care most likely explain such changes in renal outcomes. (J Thorac Cardiovasc Surg 2015;150:216-22)

See related commentary on pages $223-4$.

Transfusion of red blood cells (RBCs) has been independently associated with adverse outcomes, including mortality, infection, multi-organ dysfunction, and increased hospital length of stay (LOS) in patients undergoing cardiac surgery. ${ }^{1-4}$ Whether RBC transfusion is causally related to

From the Transfusion Research Unit ${ }^{\mathrm{a}}$ and The Australian and New Zealand Intensive Care Research Centre (ANZIC-RC), ${ }^{\mathrm{b}}$ Department of Epidemiology and Preventive Medicine, Monash University, Melbourne; Research and Development, ${ }^{c}$ Australian Red Cross Blood Service, Melbourne; Department of Haematology, ${ }^{\mathrm{d}}$ St Vincent's Hospital, Melbourne, Victoria, Australia; Sanquin-LUMC (Leiden University Medical Centre), ${ }^{\mathrm{e}}$ Center for Clinical Transfusion Research, Leiden, The Netherlands; Intensive Care Unit, ${ }^{\mathrm{f}}$ Austin Hospital, Melbourne; Intensive Care Unit, ${ }^{\mathrm{g}}$ Alfred Hospital, Melbourne; University of Melbourne Department of Surgery (Cardiothoracic Surgery), ${ }^{\text {h }}$ St Vincent's Hospital, Melbourne; Department of Surgery, ${ }^{\mathrm{i}}$ Monash Medical Centre, Monash University, Melbourne; and Department of Cardiothoracic Surgery, ${ }^{\mathrm{j}}$ Monash Medical Centre, Melbourne, Victoria, Australia.

Z.M. is the recipient of an Australian National Health and Medical Research Council (NHMRC) Postgraduate Scholarship (APP1017942). C.R. is the recipient of an Australian NHMRC Senior Research Fellowship (APP 1045862). This project was funded as part of an Australian NHMRC Partnership grant between the these outcomes is unknown, but one proposed mechanism for these effects is transfusion-related immunomodulation from leukocytes in RBC units. ${ }^{5}$

Previous randomized studies have reported benefits of leukodepleted RBCs, compared with nonleukodepleted $\mathrm{RBCs}$, in cardiac surgery, including reduced postoperative mortality ${ }^{6}$ and infection. ${ }^{7}$ However, studies evaluating potential benefits after the introduction of universal

Australian Red Cross Blood Service, the Victorian Government Department of Health, and Monash University: NHMRC ID Number 546291. Australian governments fully fund the Australian Red Cross Blood Service for the provision of blood products and services to the Australian Community. The ANZSCTS National Cardiac Surgery Database Program is funded by the Department of Health Victoria, and the Health Administration Corporation and the Clinical Excellence Commission, New South Wales.

Received for publication Oct 17, 2014; revisions received Feb 15, 2015; accepted for publication March 11, 2015; available ahead of print May 1, 2015.

Address for reprints: Zoe K. McQuilten, MBBS, Department of Epidemiology and

Preventive Medicine, Monash University, 99 Commercial Rd, Melbourne,

Victoria, Australia (E-mail: zoe.mcquilten@monash.edu).

$0022-5223 / \$ 36.00$

Copyright (C) 2015 by The American Association for Thoracic Surgery

http://dx.doi.org/10.1016/j.jtcvs.2015.03.015 

Abbreviations and Acronyms
$\mathrm{AKI}=$ acute kidney injury
$\mathrm{CI}=$ confidence interval
LOS $=$ length of stay
ICU $=$ intensive care unit
$\mathrm{OR}=$ odds ratio
$\mathrm{RBC}=$ red blood cell
$\mathrm{ULD}=$ universal leukodepletion

leukodepletion (ULD), including cardiac surgery patients, have reported conflicting results. A Canadian study performed during the implementation of ULD reported a reduction in mortality, febrile events, and antibiotic use in a cohort of cardiac surgery, orthopedic, intensive care unit (ICU), and trauma patients. ${ }^{8}$ In contrast, a United Kingdom study failed to demonstrate any reduction in infection rates or LOS in cardiac surgery and orthopedic patients after ULD was instituted. ${ }^{9}$ A before-and-after study in France, in patients undergoing abdominal aortic surgery, demonstrated no reduction in postoperative infections. ${ }^{10}$ In addition, a single-center randomized controlled study of 2780 patients in the United States found no difference in the primary outcomes of in-hospital mortality, LOS, or costs. ${ }^{11}$

Transfusion of RBCs has recently been reported to be independently associated with development of renal failure in cardiac surgery patients. ${ }^{12}$ Although the potential mechanism for this association is unknown, an inflammatory basis has been proposed. ${ }^{12}$ However, acute kidney injury (AKI) has not been widely studied as an outcome in the larger studies on potential benefits of implementation of ULD. In Australia, ULD was introduced in July 2008. We investigated whether the implementation of ULD was associated with a reduction in in-hospital mortality, infection, new renal failure, and ICU LOS in a cohort of cardiac surgery patients.

\section{METHODS}

\section{Patients and Data Collection}

All patients aged $\geq 18$ years who underwent cardiac surgery at the 6 major teaching hospitals within the Australian state of Victoria (population approximately 5.3 million) that perform this surgery, between 2005 and 2010, were included in the analysis. The Australian and New Zealand Society for Cardiac and Thoracic Surgeons Cardiac Surgery Database collects data prospectively on all patients undergoing cardiac surgery at participating sites, using a standardized dataset and definitions. Information collected includes patient demographics, comorbid conditions, preoperative medications, surgery (type, urgency, and prior surgical history), intraoperative details, and patient outcomes. ${ }^{13}$

Laboratory results, including preoperative hemoglobin level, platelet count, coagulation profile, and creatinine level, were obtained from the laboratory information system at each of the 6 hospitals. Data on the type and number of blood products transfused (including modifications such as leukodepletion) were obtained for each patient from this system. These data were merged using the hospital site, and a unique hospital identifier within the database, for each patient.

\section{Definitions}

Patients who underwent surgery between 2005 and 2010 were categorized as having had surgery either before or after the introduction of ULD. From July 1, 2008, all RBC components manufactured in Australia were leukodepleted. Before this, leukodepleted RBCs were provided to patients with specific indications, which did not include cardiac surgery, or to other patients, if extra leukodepleted units were in inventory.

Given that the individual hospital blood bank inventory would have held nonleukodepleted units, for up to 42 days after the introduction of ULD, patients were classified as being post-ULD if their surgery occurred after August 11, 2008. Patients were classified as being transfused if they received $\geq 1$ RBC units within 48 hours of surgery. This time period was chosen because previous studies have demonstrated effects of nonleukodepleted RBCs, within this perioperative time period, ${ }^{14}$ and to ensure that transfusion occurred before the outcomes of interest. In addition, patients were categorized as having received either exclusively leukodepleted RBCs, exclusively nonleukodepleted RBCs, or a mixture of the 2 .

Postoperative outcomes analyzed were in-hospital mortality, infection, AKI, and ICU LOS. Definitions for the outcomes were based on the Cardiac Surgery Database. ${ }^{13}$ Infection included $\geq 1$ of the following: pneumonia, deep sternal wound infection, and septicemia. Diagnosis of pneumonia required positive cultures of sputum or transtracheal aspirate combined with consistent clinical findings of pneumonia, including radiologic changes. Deep sternal wound infection required muscle and bone involvement as demonstrated by surgical exploration with positive cultures or treatment with antibiotics. Septicemia required positive blood cultures supported by $\geq 2$ of the following: fever, elevated white cell count, elevated and increasing C-reactive protein, or an elevated and increasing erythrocyte sedimentation rate. The definition used for AKI was acute postoperative renal insufficiency resulting in $\geq 2$ of the following: increased serum creatinine to $>200 \mathrm{micromol} / \mathrm{L}$; a doubling or greater increase in creatinine, compared with baseline preoperative value; or a new requirement for dialysis and/or hemofiltration.

\section{Statistical Analysis}

Summary statistics for continuous data are reported as mean and SD or median and interquartile range (IQR; 25 th centile to 75 th centile), as appropriate, and as number and percentage for categoric variables. Comparisons were performed using the Student $t$ test for normally distributed data, the Wilcoxon rank-sum test for non-normally distributed data, and Pearson's $\chi^{2}$ analysis for categoric data.

Logistic regression analyses explored the association between leukocyte depletion and the outcomes of mortality, infection, and renal failure, using a backward, step-wise approach. This association was analyzed by evaluating: (1) whether cardiac surgery was performed before or after ULD introduction; and (2) whether patients received only leukodepleted RBCs, compared with only nonleukodepleted RBCs (patients who received a mixture were excluded).

Variables associated with the outcomes of interest, with a $P$ value of $<.25$, were considered for the multiple logistic regression models. Pearson's correlation was used to assess variables for potential colinearity, with the more clinically relevant variable selected, when present. A total of 35 patient and procedural variables were considered for inclusion, as well as hospital site. The relationship between leukocyte depletion and ICU LOS among survivors was explored using linear regression. Natural logarithmic transformation of LOS was used for regression.

Because changes in outcomes after the introduction of ULD may have been a result of other changes in care over time, we investigated whether statistical evidence showed a differential effect of the timing of surgery on outcomes in transfused, compared with nontransfused, patients, by including an interaction term (timing of surgery $x \geq 1$ RBC units) in the regression models. Finally, given that more patients did not, versus did, 
receive transfusion, and illness severity is known to differ as a result of transfusion, we repeated the analysis, including an equal number of nontransfused patients who had been selected based on a propensity score for RBC transfusion. Nontransfused patients with the highest propensity score, based on 35 variables associated with RBC transfusion, were selected for the time periods before and after leukocyte depletion. The analysis comparing outcomes pre- and post-ULD was then repeated for transfused and an equal number of non-transfused patients selected based on the propensity score.

All analyses were performed using the statistical software package Stata 11.2 (Stata Corporation, College Station, Tex). This study had approval from the human research ethics committees at participating institutions.

\section{RESULTS}

During the study period, 16,253 patients underwent cardiac surgery. Laboratory information system data were available for $14,980(92 \%)$ of these patients, and these were included in the final analysis. Of these, 8857 (59\%) had surgery before introduction of ULD.

\section{Patient and Transfusion Characteristics}

Patient and surgical characteristics before and after ULD was introduced are shown in Table 1. A slightly higher proportion of patients were transfused with $\geq 1 \mathrm{RBC}$ units within 48 hours of surgery before ULD (3799 [43\%] vs $2525[41 \%], P=.044)$. The median number of RBC units transfused was 3 (IQR: 2-5), both before and after $\operatorname{ULD}(P=.167)$, with the range for all patients being 0 to 280.

A total of $1933(25 \%)$ patients received $\geq 3$ RBC units before ULD, and $1280(25 \%)$ received $\geq 3 \mathrm{RBC}$ units after $\operatorname{ULD}(P=.902)$. Of the 8656 who did not receive any RBC units within 48 hours of surgery, $1068(12 \%)$ received $>1$ RBC unit subsequently during their admission. Of the 6324 patients transfused with $\geq 1 \mathrm{RBC}$ unit within 48 hours of surgery, $2794(44 \%)$ received exclusively leukodepleted RBCs; 2702 (43\%) received exclusively nonleukodepleted RBCs; and $828(13 \%)$ received a mixture. Only $480(17 \%)$ of the group receiving exclusively leukodepleted RBCs had their surgery before the introduction of ULD.

\section{Association Between Leukodepletion and Mortality, Infection, and Acute Kidney Injury}

The overall rates of mortality, infection, and AKI were $445(3.5 \%), 1181(9 \%)$, and $904(7 \%)$, respectively. In transfused patients, no statistically significant reduction was found in in-hospital mortality or infection after the introduction of ULD (Table 2); however, a reduction was found in the proportion of patients with AKI $(10.5 \%$ vs $8.5 \%, P=.01)$.

After adjusting for the following factors, no difference in mortality or infection was found: hospital; age; gender; body mass index; prior myocardial infarction; comorbidities (diabetes, lung disease, peripheral or cerebrovascular disease, heart failure, dialysis); New York
Heart Association class; ejection fraction; preoperative laboratory parameters (hemoglobin level, platelet count, and creatinine level); surgical history; type and urgency of procedure; preoperative shock; preoperative medications (nitrates, antiplatelets, immunosuppressives); perfusion time; drain output in first 4 hours; and number of RBC units transfused. However, a reduction was found in AKI in post-ULD, compared with pre-ULD, patients (adjusted odds ratio [OR] $0.80,95 \%$ confidence interval [CI] 0.68-0.93, $P=.003$ ) (Table 3).

To determine whether the OR differed for pre-ULD versus post-ULD transfused patients, compared with nontransfused patients, we assessed whether there was an interaction between RBC transfusion and having cardiac surgery pre- or post-ULD for each of the outcomes. We found no significant differences in the adjusted ORs for mortality, infection, or AKI (timing of surgery $\times \geq 1$ RBC interaction: OR 0.77 [95\% CI 0.44-1.36, $P=.370$ ]; OR 1.22 [95\% CI $0.93-1.60, P=.155]$; and OR 0.85 [95\% CI 0.63-1.14], $P=.269$, respectively). Therefore, the effect of timing of surgery (pre- or post-ULD) was not different in transfused, compared with nontransfused, patients.

The analysis was repeated to examine differences in mortality, AKI, and infection, according to those who received exclusively leukodepleted, versus nonleukodepleted, RBCs. The results were similar to those from the comparison of pre-ULD versus post-ULD transfused patients, with no difference in mortality or infection, but with a reduction in AKI (adjusted OR 0.80 [95\% CI 0.65-0.98], $P=.035)$ (Table 4).

\section{Association Between Leukodepletion and Intensive Care Unit Length of Stay}

The overall median ICU LOS in survivors was 25 hours (IQR: 21-49 hours) before ULD, and 27 hours (IQR: 21-56 hours) after ULD. For transfused patients, the median ICU LOS in survivors was 39 hours (IQR: 22-74 hours) before ULD, and 39 hours (IQR: 21-74 hours) after ULD. The median ICU LOS in survivors was 39.5 hours (IQR: 22-73 hours) in those who received exclusively nonleukodepleted RBCs, and 36.5 hours (IQR: 21-72 hours) in those who received exclusively leukodepleted RBCs.

After adjusting for characteristics (as outlined earlier), both timing of surgery (adjusted coefficient 0.103 [95\% CI 0.077-0.129], $P<.001$ ) and RBC transfusion were associated with ICU LOS. However, no significant interaction was found between timing of surgery and $\mathrm{RBC}$ transfusion (timing of surgery $\times \geq 1 \mathrm{RBC}$ interaction: coefficient -0.005 [95\% CI -0.055 to 0.045 ], $P=.846$ ), again implying that the effect of timing of surgery (ie, before vs after ULD) was not different in transfused, versus nontransfused, patients. 
TABLE 1. Characteristics of all cardiac surgery patients and transfused cardiac surgery patients before and after introduction of universal leukodepletion

\begin{tabular}{|c|c|c|c|c|c|c|}
\hline \multirow[b]{2}{*}{ Characteristic } & \multicolumn{2}{|c|}{ All patients } & \multicolumn{2}{|c|}{ Transfused patients } & \multicolumn{2}{|c|}{ Nontransfused patients } \\
\hline & $\begin{array}{c}\text { Pre-ULD } \\
\mathbf{n}=\mathbf{8 8 5 7}(\mathbf{5 9} \%)\end{array}$ & $\begin{array}{c}\text { Post-ULD } \\
\mathrm{n}=\mathbf{6 1 2 3}(41 \%)\end{array}$ & $\begin{array}{c}\text { Pre-ULD } \\
\mathrm{n}=\mathbf{3 7 9 9}(60 \%)\end{array}$ & $\begin{array}{c}\text { Post-ULD } \\
\mathrm{n}=\mathbf{2 5 2 5}(\mathbf{4 0} \%)\end{array}$ & $\begin{array}{c}\text { Pre-ULD } \\
\mathrm{n}=3801(60 \%)\end{array}$ & $\begin{array}{c}\text { Post-ULD } \\
\mathrm{n}=\mathbf{2 5 2 7}(\mathbf{4 0} \%)\end{array}$ \\
\hline Age $(y)$ & $67(58-75)$ & $68(59-75)$ & $70(61-76)$ & $70(61-77)$ & $65(12)$ & $65(12)$ \\
\hline Gender, male & $6438(73)$ & $4410(72)$ & $2358(62)$ & $1562(62)$ & $2932(77)$ & $1932(77)$ \\
\hline Body mass index $\left(\mathrm{kg} / \mathrm{m}^{2}\right)$, mean $(\mathrm{SD})$ & $28(25-31)$ & $28(25-31)$ & $27(24-30)$ & $27(24-31)$ & $28(5)$ & $29(5)$ \\
\hline Diabetes & $2605(29)$ & $1824(30)$ & $1183(31)$ & $811(32)$ & $1146(30)$ & $769(30)$ \\
\hline Lung disease & $1026(12)$ & $761(12)$ & $507(13)$ & $355(14)$ & $404(11)$ & $298(12)$ \\
\hline Prior myocardial infarction & $3807(43)$ & $2421(40)$ & $1726(45)$ & $1069(42)$ & $1674(44)$ & $1013(40)$ \\
\hline Dialysis & $166(2)$ & $99(2)$ & $114(3)$ & $77(3)$ & $42(1)$ & $19(1)$ \\
\hline Congestive heart failure & $2675(30)$ & $1316(21)$ & $1435(38)$ & $707(28)$ & $1049(28)$ & 487 (19) \\
\hline EF severely reduced & $580(7)$ & $327(5)$ & $334(9)$ & $168(7)$ & $213(6)$ & $131(5)$ \\
\hline Clopidogrel within $5 \mathrm{~d}$ & $671(8)$ & $442(7)$ & $310(8)$ & $185(7)$ & $265(7)$ & $176(7)$ \\
\hline Aspirin within $7 \mathrm{~d}$ & 4127 (47) & $3327(54)$ & $1913(50)$ & $1384(55)$ & $1754(46)$ & $1374(54)$ \\
\hline Anticoagulants at time of surgery & $1576(18)$ & $1091(18)$ & $825(22)$ & $586(23)$ & $625(16)$ & $407(16)$ \\
\hline Steroids at time of surgery & $156(2)$ & $116(2)$ & $96(3)$ & $77(3)$ & $43(1)$ & $30(1)$ \\
\hline Immunosuppressive & $195(2)$ & $182(3)$ & $121(3)$ & $115(5)$ & $60(2)$ & $53(2)$ \\
\hline Inotropes & $241(3)$ & $159(3)$ & $191(5)$ & $119(5)$ & $41(1)$ & $32(1)$ \\
\hline Intravenous nitrates & $592(7)$ & $279(5)$ & $332(9)$ & $141(6)$ & $224(6)$ & 97 (4) \\
\hline Infective endocarditis & $233(3)$ & $162(3)$ & $170(4)$ & $109(4)$ & $53(1)$ & $39(2)$ \\
\hline IABP & $473(5)$ & $326(5)$ & $337(9)$ & $208(8)$ & $120(3)$ & $89(4)$ \\
\hline Shock & $226(3)$ & $154(3)$ & $176(5)$ & $111(4)$ & $43(1)$ & $30(1)$ \\
\hline \multicolumn{7}{|l|}{ Blood products in $48 \mathrm{~h}$} \\
\hline Transfused $\geq 1 \mathrm{RBC}$ unit & $3799(43)$ & $2525(41)$ & & & NA & NA \\
\hline Number of RBC units & $0(0-2)$ & $0(0-2)$ & $3(2-5)$ & $3(2-5)$ & NA & NA \\
\hline Transfused $\geq 1$ PLT unit & $1733(20)$ & $1100(18)$ & $1412(37)$ & $935(37)$ & $292(8)$ & $137(5)$ \\
\hline Transfused $\geq 1$ cryoprecipitate unit & $811(9)$ & $576(9)$ & $711(19)$ & $520(21)$ & $89(2)$ & $52(2)$ \\
\hline Transfused $\geq 1$ FFP unit & $1661(19)$ & 1170 (19) & $1379(36)$ & $1007(40)$ & $254(7)$ & $142(6)$ \\
\hline \multicolumn{7}{|l|}{ Laboratory parameters before surgery } \\
\hline APTT (sec) & $36(29-50)$ & $36(30-48)$ & $40(31-60)$ & $40(32-58)$ & $34(29-45)$ & $35(29-43)$ \\
\hline Platelet count $\times 10^{9} / \mathrm{L}$ & $279(221-365)$ & $280(219-367)$ & $282(218-378)$ & $288(219-384)$ & $276(221-354)$ & $275(219-356)$ \\
\hline Hemoglobin (g/L) & $140(125-150)$ & $138(123-149)$ & $130(115-143)$ & $129(115-142)$ & $143(131-152)$ & $141(130-151)$ \\
\hline Creatinine, $\mathrm{mmol} / \mathrm{L}$ & $90(80-110)$ & $85(72-103)$ & $90(80-120)$ & $89(74-110)$ & $90(80-110)$ & $84(71-100)$ \\
\hline \multicolumn{7}{|l|}{ Surgical characteristics } \\
\hline $\begin{array}{l}\text { Procedure other than isolated } \\
\text { CABG or valve }\end{array}$ & $2198(25)$ & $1731(28)$ & $1195(31)$ & $946(37)$ & $804(21)$ & $625(25)$ \\
\hline $\begin{array}{l}\text { Procedure urgency greater } \\
\text { than for elective }\end{array}$ & $3785(43)$ & $1659(27)$ & $1955(51)$ & $787(32)$ & $1498(39)$ & $613(24)$ \\
\hline Previous cardiac surgery & $688(8)$ & $525(9)$ & $477(13)$ & $395(16)$ & $179(5)$ & $101(4)$ \\
\hline Perfusion time (min) & $106(83-138)$ & $112(87-146)$ & $118(92-154)$ & $123(94-161)$ & $103(83-131)$ & $107(84-136)$ \\
\hline Drain output in first $4 \mathrm{~h}(\mathrm{mls})$ & $195(120-320)$ & $202(126-330)$ & $240(140-420)$ & $250(145-420)$ & $190(125-280)$ & $184(120-285)$ \\
\hline
\end{tabular}

Values are n (\%) or median (IQR), unless otherwise specified. The nontransfused patients were selected based on propensity score for RBC transfusion. ULD, Universal leukodepletion; $S D$, standard deviation; $E F$, ejection fraction; $I A B P$, intra-aortic balloon pump; $N A$, not applicable; $R B C$, red blood cell; $P L T$, platelet; $F F P$, fresh frozen plasma; $A P T T$, activated partial thromboplastin time; $C A B G$, coronary artery bypass graft.

\section{Effect of the Number of RBC Unit Transfusions}

To test whether leukocyte depletion had a doseresponse effect on outcomes, we repeated the analysis, this time considering whether the timing of surgery interacted with the number of RBC units. As in the previous analysis, no significant difference was found in the adjusted ORs in transfused, versus nontransfused, patients, including for AKI (interaction of timing of surgery $\times$ number of RBC transfusions: OR $1.01[95 \%$ CI 0.99-1.02], $P=.537$ ).

\section{Propensity-Matched Analysis}

Finally, given the differences between nontransfused patients, compared with transfused patients, we repeated the analysis, selecting an equal number of nontransfused patients based on a propensity score for RBC transfusion. Comparison of patients before and after ULD, who did not receive a transfusion, is shown in Table 1 . The median propensity score for RBC transfusion was 0.58 (IQR: $0.39-0.77$ ) for transfused patients, and 0.31 (IQR: 0.21-0.46) for nontransfused patients $(P<.001)$. 
TABLE 2. Comparison of outcomes from before and after introduction of universal leukodepletion, and for patients who received leukodepleted, versus nonleukodepleted, red blood cells in cardiac surgery transfusions

\begin{tabular}{|c|c|c|c|c|c|c|c|c|c|}
\hline \multirow[b]{2}{*}{ Outcome } & \multicolumn{3}{|c|}{ All patients, $N=14,980$} & \multicolumn{3}{|c|}{ Transfused $n=6296$} & \multicolumn{3}{|c|}{$\begin{array}{c}\text { Transfused leukodepleted or } \\
\text { nonleukodepleted } \mathrm{RBCs}^{*} \mathrm{n}=5496\end{array}$} \\
\hline & $\begin{array}{c}\text { Pre-ULD } \\
\mathbf{n}=\mathbf{8 8 5 7} \\
(\mathbf{5 9 \%})\end{array}$ & $\begin{array}{c}\text { Post-ULD } \\
n=6123 \\
(41 \%)\end{array}$ & $\begin{array}{c}P \\
\text { value }\end{array}$ & $\begin{array}{c}\text { Pre-ULD } \\
\mathbf{n}=3799 \\
(60 \%)\end{array}$ & $\begin{array}{c}\text { Post-ULD } \\
\text { n }=2525 \\
(40 \%)\end{array}$ & $\begin{array}{c}P \\
\text { value }\end{array}$ & $\begin{array}{c}\text { Nonleukodepleted } \\
\mathrm{n}=\mathbf{2 7 0 2}(\mathbf{4 3} \%)\end{array}$ & $\begin{array}{c}\text { Leukodepleted } \\
\mathrm{n}=2794(44 \%)\end{array}$ & $\begin{array}{c}P \\
\text { value }\end{array}$ \\
\hline In-hospital mortality & $294(3.3)$ & $177(2.9)$ & .139 & $240(6.3)$ & $136(5.4)$ & .125 & $145(5.4)$ & $143(5.1)$ & 680 \\
\hline Infection & $792(8.9)$ & $495(8.1)$ & .066 & $510(13.4)$ & $310(11.9)$ & .080 & $347(12.8)$ & $318(11.4)$ & .097 \\
\hline AKI & $615(7.0)$ & $110(6.1)$ & .027 & $398(10.5)$ & $215(8.5)$ & .010 & $284(10.5)$ & $236(8.5)$ & .011 \\
\hline ICU LOS (h), median (IQR) & $25(21-49)$ & $27(21-56)$ & .004 & $39(22-74)$ & $39(21-74)$ & .127 & $39.5(22-73)$ & $36.5(21-72)$ & .0323 \\
\hline
\end{tabular}

Values are $\mathrm{n}(\%)$, unless otherwise indicated. $R B C$, Red blood cell; $U L D$, universal leukodepletion; $A K I$, acute kidney injury; $I C U$, intensive care unit; $L O S$, length of stay; $I Q R$, interquartile range. *Excludes patients who received both leukodepleted and non leukodepleted RBCs.

Repeated analysis in this subset still showed no difference in the adjusted ORs for mortality, infection, or AKI before, versus after, ULD implementation, between transfused and nontransfused patients (timing of surgery $\times \geq 1$ RBC interactions: OR $0.75[95 \%$ CI $0.42-1.32, P=.313]$; OR 1.16 [95\% CI $0.89-1.54$, $P=.290]$; and OR 0.89 [95\% CI 0.65-1.23, $P=.495$ ], respectively). In addition, no difference was found for ICU LOS after adjustment (timing of surgery $x \geq 1$ RBC interaction: coefficient -0.017 [95\% CI -0.07 to 0.35 , $P=.510])$.

\section{DISCUSSION \\ Key Findings}

In this study of 14,980 consecutive cardiac surgery patients from 6 hospitals, introduction of ULD was independently associated with a reduction in AKI and ICU LOS, but not in in-hospital mortality or infection. However, these changes in outcomes were not significantly different in transfused patients from those seen in nontransfused patients, and therefore, other changes in care, over time, most likely explain such changes in renal outcomes and LOS. Although patients who received exclusively nonleukodepleted RBCs were less likely to develop AKI, most had their surgery after the introduction of ULD, and therefore, these differences in outcomes could be attributable to other changes in care, over time.

TABLE 3. Adjusted odds ratios for post-, versus pre-universal leukodepletion, for all patients

\begin{tabular}{lccc}
\hline \multicolumn{1}{c}{ Outcome } & Adjusted OR & $\mathbf{9 5} \%$ CI & $\boldsymbol{P}$ value \\
\hline In-hospital mortality & 0.96 & $0.76-1.21$ & .730 \\
Infection & 0.90 & $0.79-1.03$ & .142 \\
Acute kidney injury & 0.80 & $0.68-0.93$ & .003 \\
\hline
\end{tabular}

Odds ratios are adjusted for hospital site, patient comorbidities, surgery type, surgery urgency and prior surgery history, preoperative medications, preoperative status (including shock and use of an intra-aortic balloon pump), preoperative laboratory values, perfusion time, drain loss, and number of red blood cells transfused. $O R$, Odds ratio; $C I$, confidence interval.

\section{Relationship to Previous Studies}

Previous randomized controlled studies in cardiac surgery have reported benefits from transfusion of leukodepleted RBCs, compared with nonleukodepleted RBCs. These studies have included reduction in postoperative infection ${ }^{7}$ and mortality, ${ }^{6}$ perhaps through an effect on the postoperative pro-inflammatory state, with previous studies reporting higher interleukin-6 levels and an associated increased risk of multi-organ dysfunction (which included renal impairment) with transfusion of nonleukodepleted RBCs. ${ }^{14}$

However, studies after the introduction of ULD have reported conflicting results with regard to mortality, infection, and LOS in cardiac surgery patients. A Canadian before-and-after study, conducted during the implementation of ULD, of 14,786 patients who received transfusion after cardiac surgery, or repair of hip fracture, or during ICU admission after surgery or trauma, reported a reduction in the adjusted odds of mortality after ULD. ${ }^{8}$ However, in the subgroup analysis of the 9525 cardiac surgery patients, no significant reduction in mortality was found (adjusted OR 0.88, [95\% CI 0.72-1.07]). In contrast, a before-and-after study of 2095 consecutive patients undergoing elective coronary artery bypass grafting, or total hip and/or knee replacement in the United Kingdom, found no difference in postoperative LOS or the proportion of patients with suspected and proven postoperative infections. In the 852 transfused cardiac surgery patients, mortality was higher after introduction of ULD (OR 3.05 [95\% CI 1.11-8.37], $P=.031$ ).

More recently, the effect of leukocyte depletion on the risk of developing AKI has been investigated. Both transfusion and anemia have been independently associated with risk of AKI after cardiac surgery. ${ }^{15}$ Whether RBC transfusion is causally related is unknown; however, possible mechanisms proposed include promotion of a pro-inflammatory state, impaired tissue oxygen delivery, and exacerbation of oxidative stress. ${ }^{12}$ Romano and colleagues $^{16}$ studied 147 matched pairs of transfused patients over a period of 4 years, during which ULD was 
TABLE 4. Adjusted odds ratios for red blood cells that are exclusively nonleukodepleted versus exclusively leukodepleted

\begin{tabular}{lccc}
\hline \multicolumn{1}{c}{ Outcome } & Adjusted OR & $\mathbf{9 5} \%$ CI & $\boldsymbol{P}$ value \\
\hline In-hospital mortality & 0.97 & $0.72-1.30$ & .844 \\
Infection & 1.11 & $0.91-1.34$ & .299 \\
Acute kidney injury & 0.80 & $0.65-0.98$ & .035 \\
\hline
\end{tabular}

Odds ratios are adjusted for hospital site, patient comorbidities, surgery type, surgery urgency and prior surgery, preoperative medications, preoperative status (including shock and use of an intra-aortic balloon pump), preoperative laboratory values, perfusion time, drain loss, and number of red blood cells transfused. OR, Odds ratio; $C I$, confidence interval.

introduced, and reported a reduction in AKI from $51.7 \%$ to $41.5 \%$. Their study was a single-institution study and did not account for any trends in rates of AKI over the course of the 4-year period.

The rate of AKI in that study ${ }^{16}$ was much higher than the rate in our study, which may be partly a result of the definition used, which was a RIFLE (risk, injury, failure, loss of function, end-stage renal disease) grade of $\mathrm{R}$ (risk: least-severe grade) or greater. In our study, although ULD was associated with a reduction in the proportion of cardiac surgery patients who developed AKI, this reduction seemed to be attributable to changes in care over time, because the OR for AKI in transfused patients was not significantly different than the OR in nontransfused controls.

\section{Strengths and Limitations}

Our study has several strengths. It included a large cohort of consecutive cardiac surgery patients from 6 institutions, using prospectively collected and validated data. We addressed the issue of change in care over time, by testing for an interaction between transfusion and timing of surgery. Through this analysis, we found that the reduction in AKI observed in the transfused cohort was not significantly different than that seen in nontransfused patients and could therefore not be attributed to benefits of ULD alone. Without this comparison, we might have overestimated the potential benefits of ULD in regard to AKI. In addition, we attempted to address the inherent differences between nontransfused "control" patients, compared with transfused patients, via selection of nontransfused patients based on a propensity score for RBC. This approach did not change the findings of our study.

The study has limitations that should be considered in interpreting the results. The study is observational and uses registry data that are not designed to address this particular study question. However, the registry data used were collected prospectively on all patients, reducing the risk of observation bias and laboratory information system data were used, which provide reliable information on transfused blood products in this population. ${ }^{17}$

Despite our attempts to adjust for many important patient and procedural factors in the multivariable analysis, adjusting for all potential confounders, both measured and unmeasured, is not possible, and these may have influenced the outcomes of interest. Potential confounders include the use of antifibrinolytics, intravenous fluids, and antibiotics, which were not available for our analysis. Finally, we excluded patients who received a mixture of RBCs that were or were not leukodepleted from the subgroup comparison between patients receiving exclusively leukodepleted, versus nonleukodepleted, RBCs. By doing so, we likely excluded a cohort of higher-risk patients, because those who received both types of RBC were more likely to have received more RBCs. However, including these patients with the cohort who received only nonleukodepleted RBCs may have exaggerated the benefit of leukodepleted RBCs.

\section{Implications of Study Findings}

Studies into potential benefits of ULD are relevant, because provision of ULD is accompanied by substantial manufacturing costs, and although many countries have already adopted ULD routinely, this is not standard practice in all countries. For example, in the United States, according to the 2011 National Blood Collection and Utilization Survey Report, ${ }^{18}$ approximately $70 \%$ of whole blood/RBCs transfused in 2011were leukodepleted. In this report, approximately $73 \%$ of US transfusing facilities responded that they had a policy of ULD. In the remaining $27 \%$ of facilities, without a policy of ULD, only $10 \%$ had a policy of transfusing only leukodepleted RBCs for cardiac surgery. ${ }^{18}$ Our study did not demonstrate a benefit of ULD for cardiac surgery patients that could not be attributed to other changes in care over time. For this reason, we recommend that future before-and-after studies in transfusion include a matched cohort of nontransfused patients for this reason.

\section{CONCLUSIONS}

In our large cohort study, we did not find an association between introduction of ULD and additional improvements in mortality, infection, or AKI beyond those that probably result from other changes in care over time. Our findings are in contrast to the results of other before-and-after studies, and randomized but smaller trials, and challenge the notion that ULD provides clinically important advantages in cardiac surgery patients.

\section{Conflict of Interest Statement}

Authors have nothing to disclose with regard to commercial support.

The authors thank The Australian and New Zealand Society for Cardiac and Thoracic Surgeons (ANZSCTS) Data Management Centre, Centre of Cardiovascular Research \& Education (CCRE) in Therapeutics, Monash University: Prof Chris Reid, Dr Lavinia Tran, and Mrs Angela Brennan. 
The authors thank the ANZSCTS Database Program Steering Committee:

Mr Gil Shardey (Chair), Mr Peter Skillington, Mr Julian Smith, Mr Andrew Newcomb, Mr Siven Seevanayagam, Mr Bo Zhang, Mr Hugh Wolfenden, Mr Adrian Pick, Mr Jurgen Passage, Associate Prof Rob Baker, Prof Chris Reid, Dr Lavinia Tran, and $\mathrm{Mr}$ Andrew Clarke.

The following investigators, data managers, and institutions participated in the ANZSCTS Database: Alfred Hospital: Pick A, Duncan J; Austin Hospital: Seevanayagam S, Shaw M; Cabrini Health: Shardey G; Geelong Hospital: Morteza M, Zhang B, Bright C; Flinders Medical Centre: Knight J, Baker R, Helm J, Canning N; Jessie McPherson Private Hospital: Smith J, Baxter H; John Hunter Hospital: James A, Scaybrook S; Lake Macquarie Hospital: Dennett B, Mills M; Liverpool Hospital: French B, Hewitt N; Mater Health Services: Diqer AM, Curtis L; Monash Medical Centre: Smith J, Baxter H; Prince of Wales Hospital: Wolfenden H, Weerasinge D; Royal Melbourne Hospital: Skillington P, Wynne R; Royal North Shore Hospital: Sze D; Royal Perth Hospital: Edwards M, Wright M, Le V; Royal Prince Alfred Hospital: Wilson M, Turner L, Powell, C; Sir Charles Gairdner Hospital: Kolybaba M; St George Hospital: Fermanis G, Newbon P; St Vincent's Hospital, Victoria: Yii M, Newcomb A, Mack J, Duve K; St Vincent's Hospital, New South Wales: Spratt P, Hunter T; The Canberra Hospital: Bissaker P, Dean A; Townsville Hospital: Tam R, Farley A; Westmead Hospital: Costa R, Halaka M.

\section{References}

1. Murphy GJ, Reeves BC, Rogers CA, Rizvi SI, Culliford L, Angelini GD Increased mortality, postoperative morbidity, and cost after red blood cell transfusion in patients having cardiac surgery. Circulation. 2007;116:2544-52.

2. Bhaskar B, Dulhunty J, Mullany DV, Fraser JF. Impact of blood product transfusion on short and long-term survival after cardiac surgery: more evidence. Ann Thorac Surg. 2012;94:460-7.

3. Koch CG, Li L, Duncan AI, Mihaljevic T, Cosgrove DM, Loop FD, et al. Morbidity and mortality risk associated with red blood cell and blood-component transfusion in isolated coronary artery bypass grafting. Crit Care Med. 2006:34:1608-16.

4. Scott BH, Seifert FC, Grimson R. Blood transfusion is associated with increased resource utilisation, morbidity and mortality in cardiac surgery. Ann Card Anaesth. 2008;11:15-9.

5. Bilgin YM, Brand A. Transfusion-related immunomodulation: a second hit in an inflammatory cascade? Vox Sang. 2008;95:261-71.
6. van de Watering LM, Hermans J, Houbiers JG, van den Broek PJ, Bouter H, Boer F, et al. Beneficial effects of leukocyte depletion of transfused blood on postoperative complications in patients undergoing cardiac surgery: a randomized clinical trial. Circulation. 1998;97:562-8.

7. Bilgin YM, van de Watering LM, Eijsman L, Versteegh MI, Brand R, van Oers $\mathrm{MH}$, et al. Double-blind, randomized controlled trial on the effect of leukocyte-depleted erythrocyte transfusions in cardiac valve surgery. Circulation. 2004;109:2755-60.

8. Hebert PC, Fergusson D, Blajchman MA, Wells GA, Kmetic A, Coyle D, et al. Clinical outcomes following institution of the Canadian universal leukoreduction program for red blood cell transfusions. JAMA. 2003;289:1941-9.

9. Llewelyn CA, Taylor RS, Todd AA, Stevens W, Murphy MF, Williamson LM The effect of universal leukoreduction on postoperative infections and length of hospital stay in elective orthopedic and cardiac surgery. Transfusion. 2004; 44:489-500.

10. Baron JF, Gourdin M, Bertrand M, Mercadier A, Delort J, Kieffer E, et al. The effect of universal leukodepletion of packed red blood cells on postoperative infections in high-risk patients undergoing abdominal aortic surgery. Anesth Analg. 2002;94:529-37; table of contents.

11. Dzik WH, Anderson JK, O’Neill EM, Assmann SF, Kalish LA, Stowell CP. A prospective, randomized clinical trial of universal WBC reduction. Transfusion. 2002;42:1114-22.

12. Karkouti K. Transfusion and risk of acute kidney injury in cardiac surgery. Br J Anaesth. 2012;109(Suppl 1):i29-38.

13. Billah B, Reid CM, Shardey GC, Smith JA. A preoperative risk prediction model for 30-day mortality following cardiac surgery in an Australian cohort. Eur J Cardiothorac Surg. 2010;37:1086-92.

14. Bilgin YM, van de Watering LM, Versteegh MI, van Oers MH, Brand A. Effects of allogeneic leukocytes in blood transfusions during cardiac surgery on inflammatory mediators and postoperative complications. Crit Care Med. 2010;38:546-52.

15. Karkouti K, Wijeysundera DN, Yau TM, McCluskey SA, Chan CT, Wong PY, et al. Influence of erythrocyte transfusion on the risk of acute kidney injury after cardiac surgery differs in anemic and nonanemic patients. Anesthesiology. 2011; 115:523-30.

16. Romano G, Mastroianni C, Bancone C, Della Corte A, Galdieri N, Nappi G, et al. Leukoreduction program for red blood cell transfusions in coronary surgery: association with reduced acute kidney injury and in-hospital mortality. $J$ Thorac Cardiovasc Surg. 2010;140:188-95.

17. McQuilten ZK, Schembri N, Polizzotto MN, Akers C, Wills M, Cole-Sinclair MF, et al. Hospital blood bank information systems accurately reflect patient transfusion: results of a validation study. Transfusion. 2011;51: 943-8.

18. Whitaker BI, Hinkins S. The 2011 National Blood Collection and Utilisation Survey. Bethesda, Md: US Department of Health and Human Services; 2011.

Key Words: Leukocyte reduction procedures, coronary artery bypass, erythrocyte transfusion 